\title{
Long term follow up of percutaneous treatment for degenerated Mitroflow prosthesis with self-expanding transcatheter aortic valve implantation
}

\author{
Isaac Pascual ${ }^{1,2,3}$, Marcel Almendárez ${ }^{1,3}$, Rut Álvarez Velasco ${ }^{1,3}$, Antonio Adeba ${ }^{1,3}$, \\ Daniel Hernández-Vaquero ${ }^{1,2,3}$, Rebeca Lorca ${ }^{1,3}$, Rocío Díaz ${ }^{1,3}$, Alberto Alperi ${ }^{1}$, Héctor Cubero-Gallego ${ }^{1,3}$, \\ Jose Rozado $^{1,3}$, César Morís ${ }^{1,3,4}$, Pablo Avanzas ${ }^{1,3,4}$ \\ ${ }^{1}$ Heart Area, Hospital Universitario Central de Asturias, Asturias, Spain; ${ }^{2}$ Functional Biology Department, University of Oviedo, Asturias, Spain; \\ ${ }^{3}$ Instituto de Investigación Sanitaria del Principado de Asturias (ISPA), Asturias, Spain; ${ }^{4}$ Medicine Department, University of Oviedo, Asturias, Spain \\ Contributions: (I) Conception and design: I Pascual, P Avanzas, D Hernandez-Vaquero; (II) Administrative support: All authors; (III) Provision of \\ study materials or patients: All authors; (IV) Collection and assembly of data: All authors; (V) Data analysis and interpretation: All authors; (VI) \\ Manuscript writing: All authors; (VII) Final approval of manuscript: All authors. \\ Correspondence to: Daniel Hernández-Vaquero. Heart Area, Hospital Universitario Central de Asturias, Avda Roma sn, 33011 Oviedo, Principado de \\ Asturias, Spain. Email: dhvaquero@gmail.com.
}

Background: The durability of aortic valve bioprosthesis and the structural valve deterioration (SVD) are could be treated with valve-in-valve (VIV) transcatheter aortic valve implantation (TAVI). This technique has been proven to be a feasible procedure with good results in selected patients. The aim of this work was to assess the long-term results of this TAVI with an autoexpandable valve in patients with failed Mitroflow (MF) bioprosthetic aortic valves.

Methods: Single center, observational and prospective study that included 65 consecutive patients with symptomatic failed MF bioprosthetic aortic valve, treated with VIV-TAVI. The primary endpoints were clinical long-term events including all-cause mortality, cardiovascular mortality, re-hospitalization due to heart failure, stroke/transient ischemic attack (TIA) and endocarditis. Secondary endpoints were the absence of SVD or patient-prosthesis mismatch (PPM) and valve hemodynamics analysis at follow-up.

Results: Between March 2012 to July 2019, 65 symptomatic patients (age 80.4 45.9 years) with degenerated MF valves (numbers 19: 27.7\%; 21: 38.5\%; 23: 21.5\%; 25: 12.3\%) underwent CoreValve (n=11) or Evolut $\mathrm{R}(\mathrm{n}=54)$ implantation $(23,26$ and $29 \mathrm{~mm}$ sizes). The STS predicted risk of mortality was $6.39 \% \pm 5.62 \%$. The primary combined endpoint occurred in $32.3 \%$ of the cases. A total of 13 patients (20\%) died during follow-up, but 4 (7.3\%) from cardiovascular causes. Two patients were reported of having a stroke/TIA and 5 readmissions for cardiovascular causes were reported ( 2 of them within the first 30 days). Twenty-five patients (38.5\%) presented PPM during follow-up, being PPM severe in 15 (23.1\%).

Conclusions: Self-expanding TAVI for degenerated MF bioprosthesis has favourable long-term outcomes. It is a good option in order to avoid the risks of redo surgery in selected patients.

Keywords: Long-term; Mitroflow (MF); valve-in-valve (VIV); transcatheter aortic valve implantation (TAVI); degeneration

Submitted Dec 13, 2019. Accepted for publication Feb 15, 2020.

doi: $10.21037 /$ atm.2020.02.120

View this article at: http://dx.doi.org/10.21037/atm.2020.02.120 


\section{Introduction}

Valvular heart disease accounts for up to $10-20 \%$ of cardiac surgeries, being severe aortic stenosis the leading cause for heart valve replacement (1).

Over the last years, there has been a relative increase in the use of bioprosthesis that could be explained by the ageing population and the possibility to avoid oral anticoagulation therapy, among other causes. However, the durability of this type of prosthesis and possible structural valve deterioration (SVD) are its major concerns (2-4).

Nowadays, the standard of care for degenerated bioprosthesis remains surgical aortic valve replacement. Nevertheless, this would involve all associated risks of cardiovascular re-interventions (5).

In this context, an emerging option is valve-in-valve transcatheter aortic valve implantation (VIV-TAVI). This technique has been proven to be a feasible procedure with good results in selected patients (6-8).

The Mitroflow (MF) bovine pericardial prosthesis valve (Sorin Group Inc., Mitroflow Division; Vancouver, Canada) is known to be prone to early SVD. A recent study showed that $15.8 \%$ of MF prostheses had signs of SVD 8 years after follow-up (9). Taking into account that up to 100,000 of these valves have been implanted in Europe throughout the last 20 years, a substantial increase in the prevalence of degenerated prosthesis is expected.

There are three patterns of SVD: stenosis (40\%), regurgitation (30\%) or both (30\%). All of them have been associated with worse clinical outcomes and irreversible damage if adequate treatment is not performed $(4,10,11)$. Therefore, a prompt diagnosis and an appropriate treatment of this challenging group of patients is imperative $(12,13)$.

The main objective of this study is to evaluate the late clinical outcomes of patients with SVD MF bioprosthesis treated with VIV-TAVI.

\section{Methods}

Data was collected from all consecutive patients undergoing VIV-TAVI due to symptomatic MF bioprosthetic SVD in a single high-volume center from March 2012 to June 2019. The VIV-TAVI indication was made by a multidisciplinary heart valve team composed by experienced interventional cardiologists, clinical cardiologists, cardiac surgeons and geriatricians, following current available protocols and guidelines. Patients were prospectively included in the study and followed-up was planned. Informed consent was obtained from each patient.

\section{Baseline evaluation}

The baseline routine evaluation for anatomical characteristics included data gathered from transthoracic echocardiogram (TTE), coronary and peripheral angiography and ECGgated contrast-enhanced multi-slice computed tomography (since 2014). All the studies were performed by an experienced operator and analyzed by the same team.

\section{VIV-TAVI procedure}

Patients were admitted the day before of the procedure for preparation. Prophylactic antibiotic coverage with cephalosporins or with vancomycin in allergic patients was administered. Patients at high risk for contrast induced acute kidney injury (CI-AKI) were submitted to a hydration protocol as per standard of care.

In the catheterization laboratory, superficial sedation was intended, sparing general anesthesia for high risk patients (e.g., hemodynamically unstable, chronic obstructive lung disease), following the heart team criteria. The preferred vascular access was the femoral artery only in cases with severe calcification, tortuosity or a diameter less than $6 \mathrm{~mm}$, a surgical subclavian approach was performed. The valve size was selected according to the inner diameter of the previous prosthesis. For MF 19, 21 and 23, Evolut/Corevalve 23 valves were selected, while for MF 25, Evolut/Corevalve 26 were used. Femoral accesses were performed under ultrasound or angiography guidance and a percutaneous closure device, either the Prostar ${ }^{\circledR}$ XL percutaneous vascular surgical system (Abbott, Abbott Park, Illinois, US) or the Perclose ProGlide ${ }^{\circledR}$ (Abbott, Abbott Park, Illinois, USA) was used. Since 2018 the MANTA $^{\circledR}$ (Essential Medical, Malvern, PA, USA) vascular closure device became available at our centre and ever since then it was the routine closing device. Valve positioning and liberation followed the manufacturers recommendations. In cases with coronary ostium height less than $6 \mathrm{~mm}$ or if the virtual distance from the valve to the ostium was less than $4 \mathrm{~mm}$, a wire was placed inside the left main in order to assure coronary protection.

\section{Endpoints}

All events were classified according to the Valve Academic Research Consortium (VARC-2) definitions (12). The primary endpoints were clinical long-term events including all-cause mortality, cardiovascular mortality, re-hospitalization due to heart failure, stroke/transient 
ischemic attack (TIA) and endocarditis. Secondary endpoints were the absence of SVD or patient-prosthesis mismatch (PPM) and valve hemodynamics analysis at follow-up.

\section{Definitions}

Mortality: all-cause mortality during the follow-up period.

Cardiovascular mortality: mortality defined by at least one of these criteria: every death due to a cardiac cause, unexpected or with unknown cause, deaths related to any procedure complication or caused by treatment of any complication of the procedure and deaths due to vascular but non-coronary cause (14).

Late prosthetic failure: mean aortic valve gradient $\geq$ $20 \mathrm{mmHg}$ from baseline with a concomitant decrease in the aortic valve area $>0.6 \mathrm{~cm}^{2}$ or moderate to severe aortic regurgitation (15).

PPM: indexed orifice area $\leq 0.85 \mathrm{~cm}^{2} / \mathrm{m}^{2}$ and severe PPM as an indexed effective orifice area $\leq 0.65 \mathrm{~cm}^{2} / \mathrm{m}^{2}(15)$.

Procedural success: absence of significant aortic regurgitation, intraprocedural death and optimal implantation according to the primary operator.

\section{Follow-up}

Periodical clinical follow-ups at 3 months and yearly from the baseline procedure were performed personally by a trained interventional cardiologist or cardiac surgeon with TAVI experience. Routine echocardiographic was performed yearly. There were no loses reported.

\section{Statistical analysis}

The statistical analysis was performed using Stata 15.2 (Stata Corp. LP, USA). Categorical variables are expressed as numbers (percentages). Quantitative variables were analyzed descriptively reporting mean \pm standard deviation (SD) in case of normal distribution and median; 25th to 75 th interquartile range (IQR) otherwise. Wilcoxon's rank sum test was used to compare ordinal variables and paired Student's $t$-test for continuous variables. Univariable Cox proportional hazard models were used to identify the factors associated with the cumulative primary end-point. Time to event curves was calculated using Kaplan-Meier curves. A P value of $<0.05$ was considered statistically significant.

\section{Results}

\section{Baseline characteristics}

Between March 2012 and July 2019, 65 consecutive patients were referred for VIV-TAVI procedure and included in this study. The mean age was $80.4 \pm 5.9$ years, with a similar sex distribution (50.8\% were male). Baseline characteristics are represented in Table 1. The average STS score was 6.39 55.62 and EuroSCORE II $8.86 \pm 5.17$. All the patients were diagnosed with SVD. A combined mechanism of stenosis and regurgitation was the most frequent form of disfunction (38.5\%), followed by regurgitation (33.9\%) and stenosis $(27.7 \%)$.

\section{Procedural and short-term results}

The procedure was performed without general anaesthesia in $66.1 \%$. The preferred vascular access was femoral (93.8\%). Evolut $\mathrm{R}$ was implanted in $83.1 \%$ and the Corevalve revalving system in the rest of patients. For MF sizes 19,21 and $23 \mathrm{~mm}$ a number 23 valve was implanted (87\%). Only $13 \%$ of patients had a MF $25 \mathrm{~mm}$, requiring a number 26 valve. Procedural data is detailed in Table 2.

The procedure was successful in $98.5 \%$ of the cases. In the first 30 days there were 2 cardiovascular deaths (3.1\%), 1 TIA $(1.5 \%)$ and 5 readmissions $(7.7 \%)$, but only 2 of them for cardiovascular causes. There were no cases of severe valve dysfunction. According to VARC-2 definitions, 4 mayor and 2 minor vascular access complications occurred. The mean gradient, peak gradient, and valve area at discharge were $13.3 \mathrm{mmHg}, 27.2 \mathrm{mmHg}$ and $1.14 \mathrm{~cm}^{2}$, respectively. Only 3 patients required a permanent pacemaker at discharge (4.62\%). PPM was observed in 34 patients (52.3\%), with severe PPM in 21 (32.3\%).

\section{Late clinical outcomes}

The median follow-up was 28.3 months (IQR, 16.9 to 60.4 months). The primary combined endpoint (all cause death, Stroke/TIA, re-hospitalization due to heart failure, stroke/TIA and endocarditis) occurred in $32.3 \%$ of the cases. A total of 13 patients (20\%) died during follow-up, but only 4 (7.3\%) from cardiovascular causes. Only 2 patients were reported of having a stroke/TIA and 5 readmissions for cardiovascular causes were reported ( 2 of them within the first 30 days). The Kaplan-Meier curves detailing the main events are shown in Figure 1. In the univariate 
Table 1 Basal clinical characteristics $(\mathrm{n}=65)$

\begin{tabular}{|c|c|}
\hline Variable & Value \\
\hline Age, years (range) & $80.4 \pm 5.9$ \\
\hline Male gender, n (\%) & $33(50.8)$ \\
\hline Body mass index, $\mathrm{kg} / \mathrm{m}^{2}$ & $26.4 \pm 3.7$ \\
\hline \multicolumn{2}{|l|}{ Cardiovascular risk factors, $\mathrm{n}(\%)$} \\
\hline Arterial hypertension & $34(52.3)$ \\
\hline Diabetes mellitus & $18(27.7)$ \\
\hline Dyslipidemia & $27(41.5)$ \\
\hline Smoking habit & $6(9.2)$ \\
\hline \multicolumn{2}{|l|}{ Cardiovascular history, n (\%) } \\
\hline Extracardiac arteriopathy & $3(4.6)$ \\
\hline Prior stroke & $5(7.7)$ \\
\hline Prior AMI & $7(10.8)$ \\
\hline Chronic kidney failure, n (\%) & $31(47.7)$ \\
\hline Pacemarker implantation, n (\%) & $11(16.9)$ \\
\hline \multicolumn{2}{|l|}{ Risk score } \\
\hline STS score, $\%$ & $6.4 \pm 5.6$ \\
\hline EuroSCORE II, \% & $8.9 \pm 5.2$ \\
\hline Logistic EuroSCORE, \% & $24.0 \pm 15.1$ \\
\hline \multicolumn{2}{|c|}{ Functional class at SVD diagnosis, $\mathrm{n}(\%)$} \\
\hline NYHA I/IV & $0(0)$ \\
\hline NYHA II/IV & $12(18.5)$ \\
\hline NYHA III/IV & $38(58.5)$ \\
\hline NYHA IV/IV & $15(23.1)$ \\
\hline \multicolumn{2}{|l|}{ Mitroflow bioprosthesis sizes (mm) } \\
\hline 19 & $18(27.7)$ \\
\hline 21 & $25(38.5)$ \\
\hline 23 & $14(21.5)$ \\
\hline 25 & $8(12.3)$ \\
\hline \multicolumn{2}{|c|}{ Parameters of degenerated Mitroflow bioprosthesis } \\
\hline \multicolumn{2}{|l|}{ Type of degeneration } \\
\hline Regurgitation & $22(33.9)$ \\
\hline Stenosis & $18(27.7)$ \\
\hline Mixed & $25(38.5)$ \\
\hline
\end{tabular}

Table 1 (continued)
Table 1 (continued)

\begin{tabular}{lc}
\hline Variable & Value \\
\hline Peak gradient, $\mathrm{mmHg}$ & $62.5 \pm 28.4$ \\
Mean gradient, $\mathrm{mmHg}$ & $34.4 \pm 16.0$ \\
Aortic valve area & $1.02 \pm 0.41$ \\
Aortic regurgitation (grade III-IV), $\mathrm{n}(\%)$ & $42(64.6)$ \\
LVEF, \% & $54.7 \pm 12.6$ \\
Time from surgery to degeneration, years & $8.4 \pm 2.2$ \\
\hline
\end{tabular}

Table 2 Procedural data

\begin{tabular}{lc}
\hline Variable & Value \\
\hline General anesthesia, $\mathrm{n}(\%)$ & $22(33.9)$ \\
Vascular access, $\mathrm{n}(\%)$ & $55(84.6)$ \\
Right femoral & $6(9.2)$ \\
Left femoral & $4(6.2)$ \\
Left axilar & \\
Devices, $\mathrm{n}(\%)$ & $11(16.9)$ \\
Corevalve & $54(83.1)$ \\
Evolut & \\
Valve sizes (mm), $\mathrm{n}(\%)$ & $56(86.2)$ \\
23 & $8(12.3)$ \\
26 & $1(1.5)$ \\
29 & 14.09 .1 \\
Peak to peak post TAVI gradient, mmHg & \\
Aortic regurgitation post TAVI, $\mathrm{n}(\%)$ & $3(1.5)$ \\
Grade 0 & $39(60.0)$ \\
Grade I & $22(33.8)$ \\
Grade II & $3(4.6)$ \\
Grade III & \\
Grade IV & \\
\hline & \\
\hline
\end{tabular}

analysis there were no significant predictors (Table 3). However, age (HR 1.09; CI: 0.96-1.24), a higher STS score (HR 1.06; CI: 0.99-1.13) and the presence of previous chronic kidney disease (HR 2.33; CI: 0.96-5.67) showed a tendency towards the combined clinical events at follow-up. 

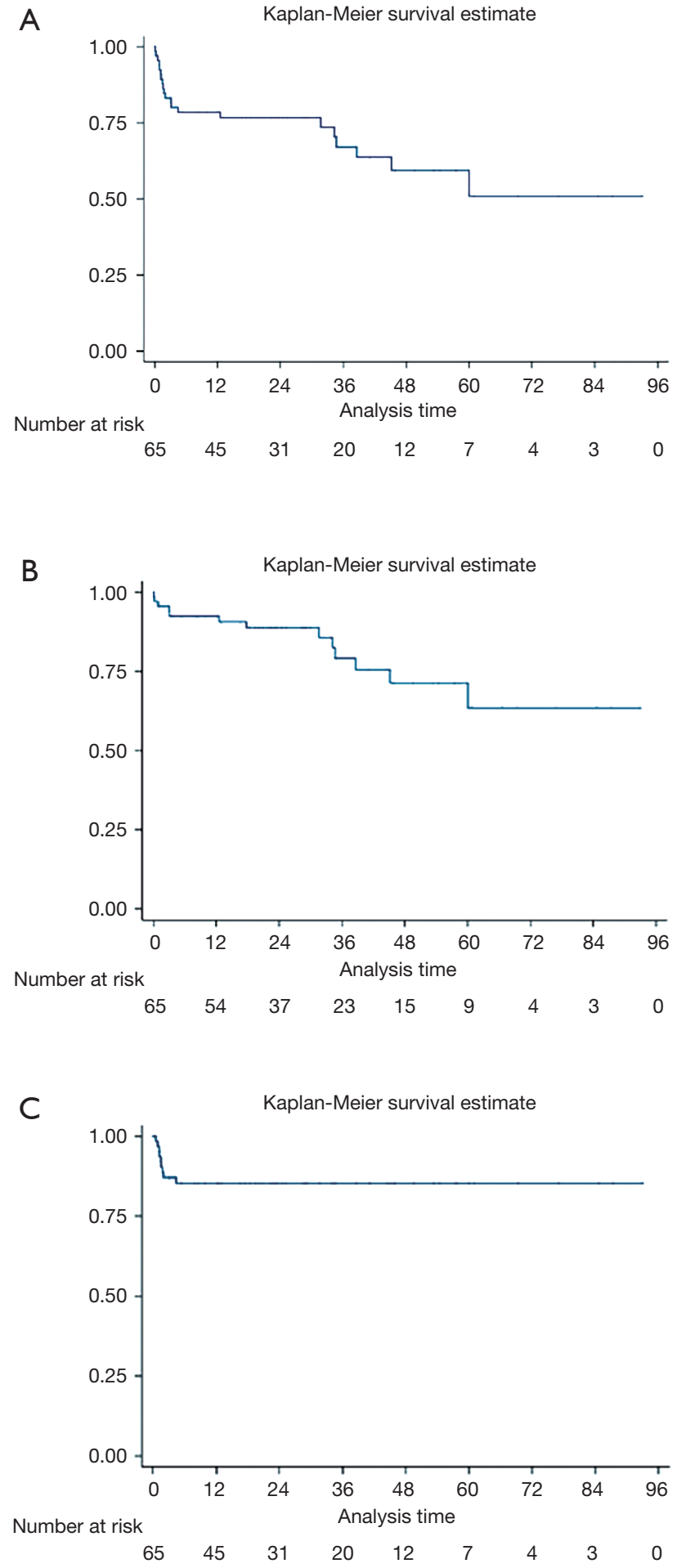

Figure 1 Kaplan-Meier curves for clinical events up to 7-year follow-up. (A) Primary End-point: all-cause mortality, stroke/TIA and cardiovascular re-hospitalization; (B) all-cause mortality; (C) cardiovascular re-hospitalization free survival.
Table 3 Univariable model for determining the factors associated with late cumulative primary end-point

\begin{tabular}{lcc}
\hline \multirow{2}{*}{ Factors } & \multicolumn{2}{c}{ Univariable model } \\
\cline { 2 - 3 } & Hazard ratio $(95 \% \mathrm{Cl})$ & P value \\
\hline Age, years & $1.09(0.96-1.24)$ & 0.18 \\
Chronic kidney disease & $2.33(0.96-5.67)$ & 0.06 \\
LVEF <50\% & $1.54(0.54-3.33)$ & 0.52 \\
Previous PPM & $1.78(0.66-4.81)$ & 0.26 \\
STS & $1.06(0.99-1.13)$ & 0.08 \\
ViV PPM & $1.02(0.43-2.42)$ & 0.97 \\
\hline
\end{tabular}

The main valve hemodynamics are outlined in Table 4 and Figure 2. All echocardiographic data was obtained from the latest study performed. The median time from the TAVI procedure to the latest TTE was 24.2 months (IQR, 1338 months). The mean gradient, peak gradient and valve area remained steady over time: 20.3 vs. $18.8(\mathrm{P}=0.175), 39.6$ vs. $35.2(\mathrm{P}=0.013)$ and 1.3 vs. $1.3(\mathrm{P}=0.728)$, respectively. The same tendency was observed in aortic regurgitation (Figure 3). There were only 2 patients (3.1\%) presenting with valve deterioration. Nevertheless, 25 patients (38.5\%) presented PPM during follow-up, being PPM severe in $15(23.1 \%)$ There were no significant changes in left ventricular ejection fraction after VIV-TAVI implantation.

At baseline, 43 patients (81.54\%) were in NYHA class III-IV, whereas on the last follow-up, 49 patients (94\%) were in NYHA class I-II $(\mathrm{P}<0.00001)$. There were no new permanent pacemaker implantations in the long-term evaluation.

\section{Discussion}

The main objective was to assess the late outcomes of patients with SVD treated with VIV-TAVI. This study confirmed the safety and feasibility of the VIV-TAVI procedure. However, the main result of this study was the ascertainment of an overall low rate of adverse events and the maintenance of a stable hemodynamic profile over the time, suggesting an acceptable long-term durability of these procedures.

All of the patients included were carriers of a MF bioprosthesis and showed a similar distribution of SVD mechanism (stenosis, regurgitation or both). We designed this prospective registry to include all consecutive patients 
Table 4 Valve hemodynamic data examinations at discharge and follow-up

\begin{tabular}{|c|c|c|c|}
\hline Variable & Discharge & Follow-up & $P$ value \\
\hline Mean gradient ${ }^{*}$ & $20.3(17.3-23.1)$ & 18.8 (15.5-22.0) & 0.175 \\
\hline Aortic valve area* & $1.3(1.1-1.4)$ & $1.3(1.1-1.5)$ & 0.728 \\
\hline \multicolumn{4}{|l|}{ Aortic regurgitation } \\
\hline Mild $^{\star \star}$ & $36.5 \%$ & $25.5 \%$ & \\
\hline Moderate ${ }^{\star \star}$ & $0 \%$ & $3.9 \%$ & \\
\hline Severe** & $0 \%$ & $0 \%$ & \\
\hline LV function* & $54.2(51.0-57.4)$ & $57.5(54.3-60.7)$ & 0.017 \\
\hline
\end{tabular}

Data are shown as \% or median (range). ${ }^{*}$, Paired $t$-test for cuantitative variables; ${ }^{*}$, Wilcoxon matched-pairs signed rank test for ordinal variables.

A
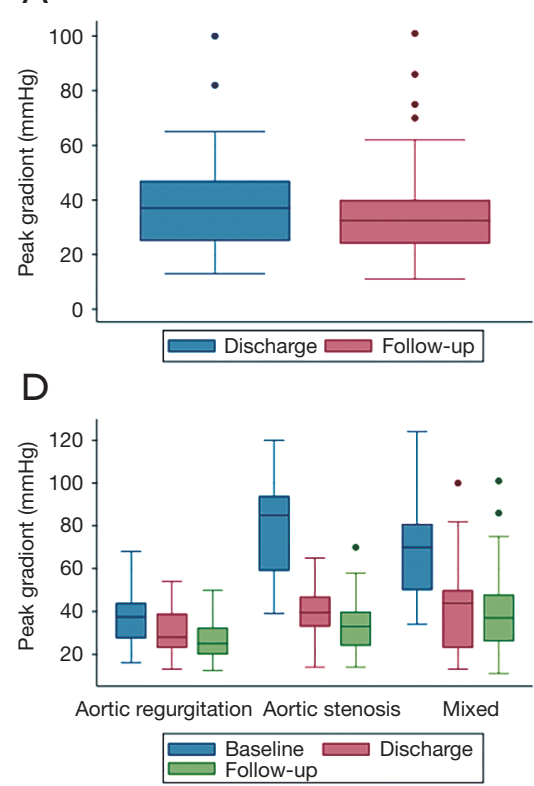

B

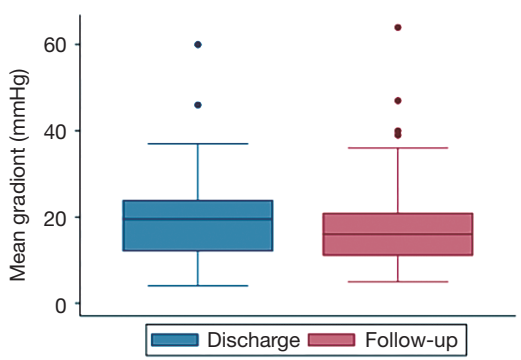

E

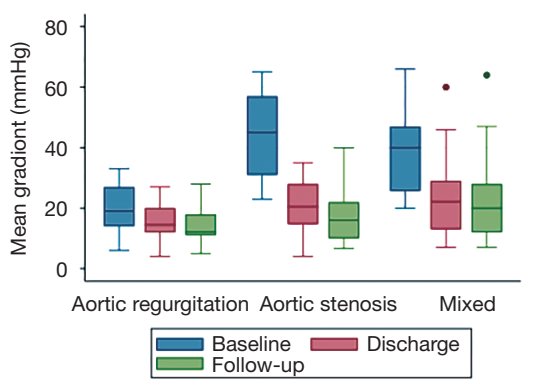

C

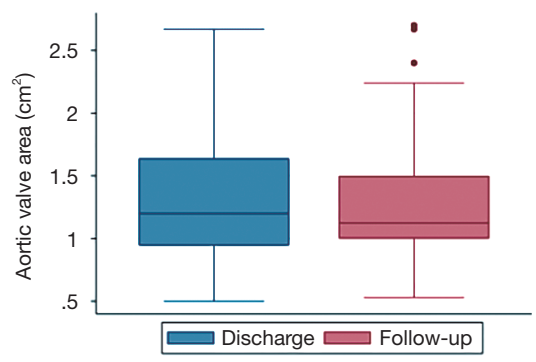

$\mathrm{F}$

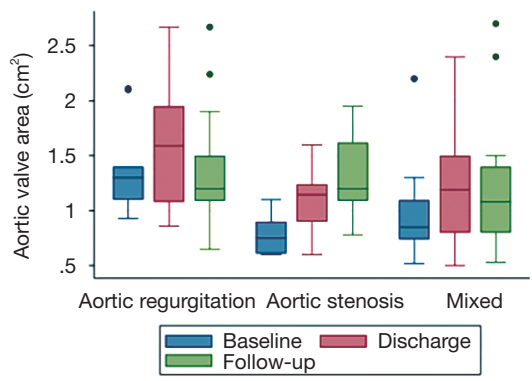

Figure 2 Box plot of echocardiographic data. (A) Peak gradient; (B) mean gradient; (C) aortic valve area at discharge and follow-up. Box plot of echocardiographic data. (D) Peak gradient; (E) mean gradient; (F) aortic valve area at baseline, discharge and follow-up by type of degeneration.

being treated with a VIV-TAVI. All the patients were treated with the Medtronic CoreValve Revalving System and its upgraded version the Evolut R System (Medtronic Inc, Minneapolis, Minnesota, USA). One of the main strengths of this study is the homogenous sample achieved: a cohort of patients with SVD from the same kind of bioprosthesis (MF valve), all treated with the same self- expanding system.

Procedural was successful in $98.5 \%$ of the cases (1 patient presented grade III aortic regurgitation after TAVI), with a 30 -day mortality rate of $3.1 \%$. This results are similar to those published in previous VIV studies $(8,16,17)$. Like other VIV-TAVI studies, the rate of new permanent pacemaker at discharge was lower than the one reported in 

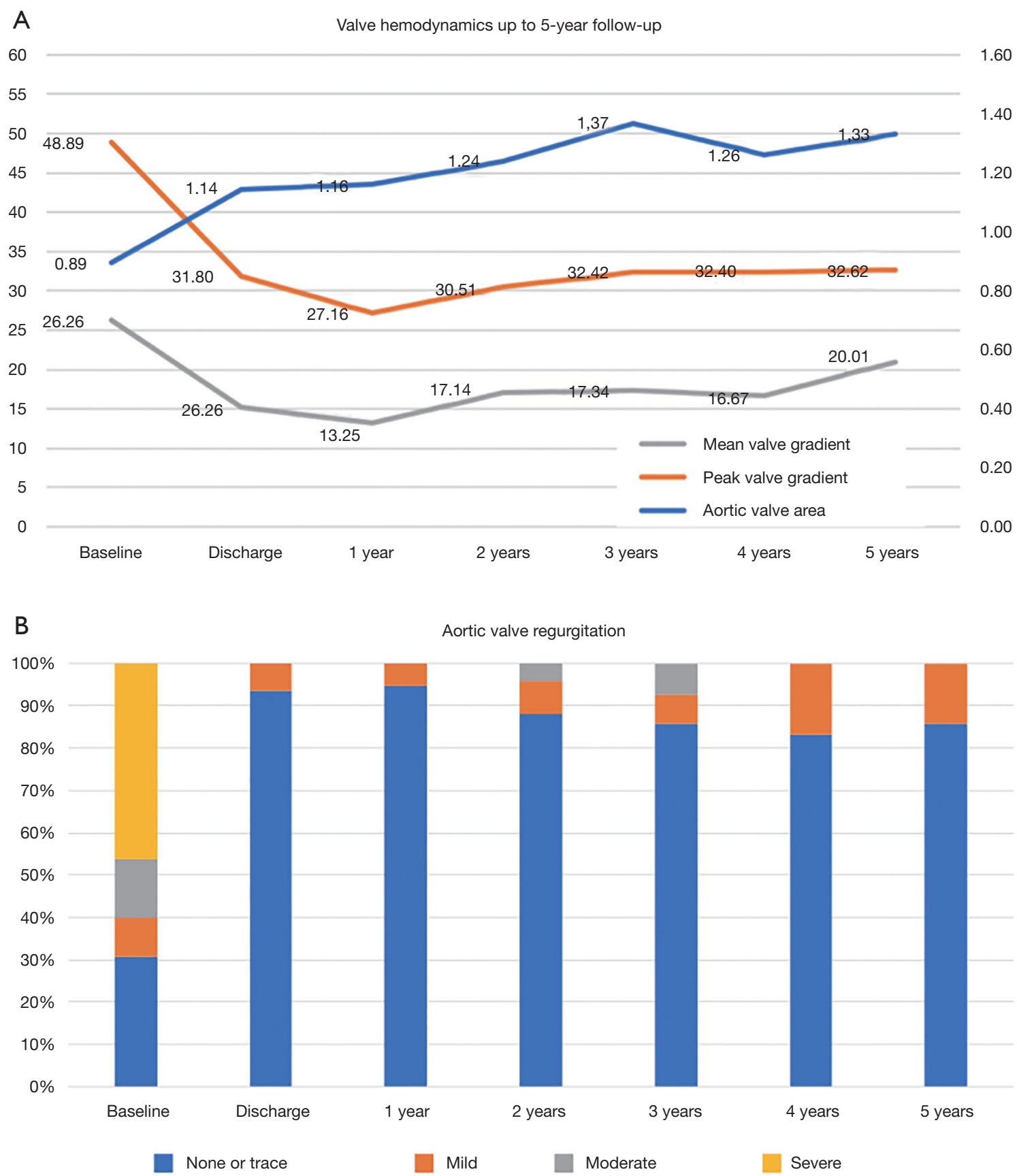

Figure 3 Valve hemodynamics at baseline, discharge and up to 5-year follow-up. (A) Mean aortic gradient, peak aortic gradient and aortic valve area; (B) aortic valve regurgitation.

TAVI for native valves (4.62\%). This could be explained by the possible protective effect that the previous bioprosthesis may exert (18-20).

The long-term follow-up was 28.8 months (IQR, 17.4-60.9 months) and all combined events including all- cause mortality, cardiovascular mortality, stroke/TIA and readmissions were present in 21 patients $(32.3 \%)$. The rate of all-cause mortality was $20 \%$ (13 deaths during the follow-up), and the overall rate of cardiovascular death was $7.3 \%(21,22)$. In comparison to TAVI in native valves, the 
mortality rate seems lower than reported. However, as these samples are not comparable due to significant differences in baseline characteristics, caution should be taken when interpreting this data. Previous VIV-TAVI registries have demonstrated slightly higher mortality rates. However, those studies analyzed different types of bioprosthesis and used a wide range of self-expandable and balloonexpandable valves (23).

Initial gradients after VIV-TAVI implantation were higher compared to those after TAVI in native valves, and AVA was smaller. However, these values remained definitely stable throughout the follow-up. Previous PPM and smaller valve sizes have been associated with this phenomenon. On that account, the MF valve frame in which the new selfexpanding prosthesis is to be deployed may be playing a pivotal role in determining such gradients $(8,10,19)$.

PPM after VIV-TAVI was observed in 25 patients (38.5\%) during follow-up and only 15 (23.1\%) presented severe PPM. Previous studies have reported rates ranging from $24.6 \%$ to $58.4 \%$, and it has been associated with worse clinical outcomes $(6,24)$. This association was not significant in this analysis, probably due to the sample size. Novel strategies that aim to reduce PPM, such as fracturing of the previous valve ring, are being developed with promising results. However, larger clinical trials are required and there is still limited experience to identify the patients that would benefit from this strategy $(25,26)$.

This study has two main e limitations. On the one hand, it is a single-centre study with a small sample size. On the other hand, although the data collection of the registry is prospective, the analysis of variables and predictors was performed in a retrospective manner. Despite these limitations, this is the largest cohort of patients reported to date with SVD of MF bioprostheses treated with a selfexpanding VIV-TAVI.

\section{Conclusions}

VIV-TAVI for SVD MF bioprosthesis is a safe procedure and a valid alternative to surgery in a selected group of patients in order to avoid the risks of redo surgery. This registry showed a high rate of success, low intraprocedural complications, low prevalence of long-term clinical adverse events and stable valve hemodynamics over time.

\section{Acknowledgments}

Funding: None.

\section{Footnote}

Provenance and Peer Review: This article was commissioned by the Guest Editor (Daniel Hernández-Vaquero) for the series "Structural Heart Disease: The Revolution" published in Annals of Translational Medicine. The article was sent for external peer review organized by the Guest Editor and the editorial office.

Conflicts of Interest: All authors have completed the ICMJE uniform disclosure form (available at http://dx.doi. org/10.21037/atm.2020.02.120). The series "Structural Heart Disease: The Revolution" was commissioned by the editorial office without any funding or sponsorship. DHV served as the unpaid Guest Editor of the series and serves as an unpaid editorial board member of Annals of Translational Medicine from Aug 2019 to Jul 2021. CM reports other from Medtronic, outside the submitted work. The authors have no other conflicts of interest to declare.

Ethical Statement: The authors are accountable for all aspects of the work in ensuring that questions related to the accuracy or integrity of any part of the work are appropriately investigated and resolved. The study was conducted in accordance with the Declaration of Helsinki (as revised in 2013). The study was approved by the IRB of our institution with the reference number 29/16. Informed consent was obtained from each patient.

Open Access Statement: This is an Open Access article distributed in accordance with the Creative Commons Attribution-NonCommercial-NoDerivs 4.0 International License (CC BY-NC-ND 4.0), which permits the noncommercial replication and distribution of the article with the strict proviso that no changes or edits are made and the original work is properly cited (including links to both the formal publication through the relevant DOI and the license). See: https://creativecommons.org/licenses/by-nc-nd/4.0/.

\section{References}

1. Iung B, Vahanian A. Epidemiology of valvular heart disease in the adult. Nat Rev Cardiol 2011;8:162-72.

2. Maganti M, Rao V, Armstrong S, Feindel CM, Scully HE, David TE. Redo Valvular Surgery in Elderly Patients. Ann Thorac Surg 2009;87:521-5.

3. Otto CM, Prendergast B. Aortic-valve stenosis - From patients at risk to severe valve obstruction. $\mathrm{N}$ Engl J Med 
2014;371:744-56.

4. Diaz R, Hernandez-Vaquero D, Alvarez-Cabo R et al. Long-term outcomes of mechanical versus biological aortic valve prosthesis: Systematic review and meta-analysis. J Thorac Cardiovasc Surg 2019;158:706-714.e18.

5. Lopez S, Meyer P, Teboul J, et al. Transcatheter valve-invalve implantation in a degenerated very small Mitroflow prosthesis. Interact Cardiovasc Thorac Surg 2018;27:850-5.

6. Dvir D, Webb JG, Bleiziffer S, et al. Transcatheter aortic valve implantation in failed bioprosthetic surgical valves. JAMA 2014;312:162-70.

7. Leontyev S, Borger MA, Davierwala P, et al. Redo aortic valve surgery: Early and late outcomes. Ann Thorac Surg 2011;91:1120-6.

8. de Freitas Campos Guimarães L, Urena M, Wijeysundera HC, et al. Long-Term Outcomes After Transcatheter Aortic Valve-in-Valve Replacement. Circ Cardiovasc Interv 2018;11:e007038.

9. Díaz R, Hernández-Vaquero D, Silva J, et al. Early Structural Valve Deterioration of the Mitroflow Aortic Bioprosthesis: Will the New Anticalcification Treatment Change Anything? Response. Rev Esp Cardiol (Engl Ed) 2017;70:1153.

10. Pascual I, Avanzas P, Hernández-Vaquero D, et al. Selfexpanding transcatheter aortic valve implantation for degenerated Mitroflow bioprosthesis: Early outcomes. Int J Cardiol 2019;287:53-8.

11. Díaz R, Hernandez-Vaquero D, Silva J, et al. Real Structural Valve Deterioration of the Mitroflow Aortic Prosthesis: Competing Risk Analysis. Rev Esp Cardiol 2017;70:1074-81.

12. Sénage T, Le Tourneau T, Foucher Y, et al. Early structural valve deterioration of mitroflow aortic bioprosthesis: Mode, incidence, and impact on outcome in a large cohort of patients. Circulation 2014;130:2012-20.

13. Joshi V, Prosser K, Richens D. Early prosthetic valve degeneration with Mitroflow aortic valves: Determination of incidence and risk factors. Interact Cardiovasc Thorac Surg 2014;19:36-40.

14. Kappetein AP, Head SJ, Généreux P, et al. Updated standardized endpoint definitions for transcatheter aortic valve implantation: the Valve Academic Research Consortium-2 consensus document†. Eur Heart J 2012;33:2403-18.

15. Capodanno D, Petronio AS, Prendergast B, et al. Standardized definitions of structural deterioration and valve failure in assessing long-term durability of transcatheter and surgical aortic bioprosthetic valves: A consensus statement from the European Association of Percutaneous Cardiovascular Interventions (EAPCI) endorsed by the European Society of Cardiology (ESC) and the European Association for Cardio-Thoracic Surgery (EACTS). Eur Heart J 2017;38:3382-90.

16. Spaziano M, Mylotte D, Thériault-Lauzier P, et al. Transcatheter aortic valve implantation versus redo surgery for failing surgical aortic bioprostheses: A multicentre propensity score analysis. EuroIntervention 2017;13:1149-56.

17. Gozdek M, Raffa GM, Suwalski P, et al. Comparative performance of transcatheter aortic valve-in-valve implantation versus conventional surgical redo aortic valve replacement in patients with degenerated aortic valve bioprostheses: Systematic review and meta-analysis. Eur J Cardiothorac Surg 2018;53:495-504.

18. Auffret V, Puri R, Urena M, et al. Conduction disturbances after transcatheter aortic valve replacement: Current status and future perspectives. Circulation 2017;136:1049-69.

19. Sang SLW, Beute T, Heiser J, et al. Early Outcomes for Valve-in-valve Transcatheter Aortic Valve Replacement in Degenerative Freestyle Bioprostheses. Semin Thorac Cardiovasc Surg 2018;30:262-8.

20. Adamo M, Fiorina C, Curello S, et al. Self-expanding transcatheter aortic valve implantation for degenerated small Mitroflow bioprosthesis: Early and midterm outcomes. EuroIntervention 2017;13:e1032-e1039.

21. Virtanen MPO, Eskola M, Jalava MP, et al. Comparison of Outcomes After Transcatheter Aortic Valve Replacement vs Surgical Aortic Valve Replacement Among Patients With Aortic Stenosis at Low Operative Risk. JAMA Netw open 2019;2:e195742.

22. Gleason TG, Reardon MJ, Popma JJ, et al. 5-Year Outcomes of Self-Expanding Transcatheter Versus Surgical Aortic Valve Replacement in High-Risk Patients. J Am Coll Cardiol 2018;72:2687-96.

23. Didier R, Eltchaninoff H, Donzeau-Gouge P, et al. Five-year clinical outcome and valve durability after transcatheter aortic valve replacement in high-risk patients FRANCE-2 registry. Circulation 2018;138:2597-607.

24. Pibarot $P$, Simonato $M$, Barbanti $M$, et al. Impact of Pre-Existing Prosthesis-Patient Mismatch on Survival Following Aortic Valve-in-Valve Procedures. JACC Cardiovasc Interv 2018;11:133-41.

25. Sathananthan J, Sellers S, Barlow AM, et al. Valve-in-Valve Transcatheter Aortic Valve Replacement and Bioprosthetic Valve Fracture Comparing Different Transcatheter Heart Valve Designs: An Ex Vivo Bench Study. JACC Cardiovasc 
Interv 2019;12:65-75.

26. Nielsen-Kudsk JE, Andersen A, Therkelsen CJ, et al.

High-pressure balloon fracturing of small dysfunctional
Mitroflow bioprostheses facilitates transcatheter aortic valve-in-valve implantation. EuroIntervention 2017;13:e1020-e1025.
Cite this article as: Pascual I, Almendárez M, Álvarez Velasco R, Adeba A, Hernández-Vaquero D, Lorca R, Díaz R, Alperi A, Cubero-Gallego H, Rozado J, Morís C, Avanzas P. Long term follow up of percutaneous treatment for degenerated Mitroflow prosthesis with self-expanding transcatheter aortic valve implantation. Ann Transl Med 2020;8(15):955. doi: 10.21037/ atm.2020.02.120 